\title{
New ways of organizing product introductions
}

\author{
Martina Berglund ${ }^{\mathrm{a},{ }^{*}}$, Ulrika Harlin ${ }^{\mathrm{b}, \mathrm{c}}$ Maria Gustavsson ${ }^{\mathrm{d}}$ and Kristina Säfsten ${ }^{\mathrm{e}}$ \\ ${ }^{a}$ Division of Quality Technology and Management, Department of Management and Engineering, Linköping \\ University, SE-581 83 Linköping, Sweden \\ ${ }^{\mathrm{b}}$ Swerea IVF, Box 104, SE-43122 Mölndal, Sweden \\ ${ }^{c}$ Department of Product and Production Development, Chalmers University of Technology, SE-412 96, Göteborg, \\ Sweden \\ ${ }^{d}$ Department of Behavioral Sciences and Learning, Linköping University, SE-581 83 Linköping, Sweden \\ ${ }^{e}$ Department of Industrial Engineering and Management, School of Engineering, Jönköping University, SE-551 11 \\ Jönköping, Sweden
}

\begin{abstract}
The aim of this paper is to describe and reflect on an interactive research approach used to address the challenges on how to improve product introductions, the part of the product realization process associated with the transfer of a product from product development to serial production. In the interactive research approach, research results as well as improvement of practice are given equal importance. The collaboration between researchers and practitioners therefore addresses both the focus and the process of the change. The approach includes four main iterative steps: 1) mapping/diagnosis, 2) feedback of results, 3) participation in development activities, and 4) follow-up/evaluation. The paper reports findings from interactive research in one company within office product industry and one company group, consisting of three company units within the engine industry. Preliminary findings indicate that the participating companies afterwards work in a more structured way with product introductions and that the employees have gained deeper knowledge about product introductions as well as experienced the advantages of working across functional boundaries. Furthermore, the interactive research approach is suitable to run projects from an ergonomics perspective as it focuses on developing both practice and theory, it is human-centered, and it emphasizes broad participation from practitioners.
\end{abstract}

Keywords: Interactive research, learning, research and practice, product and production integration, industry

\section{Introduction}

Company success includes efficient product introductions to reach set targets on cost, quality, and volume in time [1]. A product introduction is here defined as the period when the new product or product version is transferred to production, and the product and production system are adapted to each other [2]. Activities include how easy it is to produce the product, development of the production system and ensuring production [3]. Product introductions involve several groups of employees from different departments and may therefore be considered a large-scale complex work system. It is common that a number of more or less unexpected events need to be handled, why a product introduction often is characterized by fire-fighting activities [4,5]. This situation leaves little time for reflection and learning [6]. As product introductions today have an increasing frequency [7], high demands are put on the organization as well as how individual competences are utilized in the organization [8].

This paper reports findings from the ongoing fouryear interactive research project KNOP - Learning and Competence Driven Product Introduction for Swedish Manufacturing Industry. The project aims at

* Corresponding author. E-mail: martina.berglund@liu.se 
identifying and developing learning, work methods, new ways of collaboration, and management practices that strengthen innovation capability and collective competence in relation to product introductions.

The specific objective of this paper is to highlight and reflect on the interactive approach between researchers and practitioners chosen to address the challenges on how to improve the PI process.

\section{Interactive research approach}

Interactive research is an action-learning methodology, in which different actions are carried out to solve problems in practice [9]. In the interactive research approach research results and improvement of practice are regarded as equally important. The approach includes four main steps: 1) mapping/diagnosis, 2) feedback of results, 3) participation in development activities, and 4) followup/evaluation. In the case of the project KNOP which focuses on learning in relation to product introductions, the approach may be illustrated as in Figure 1.

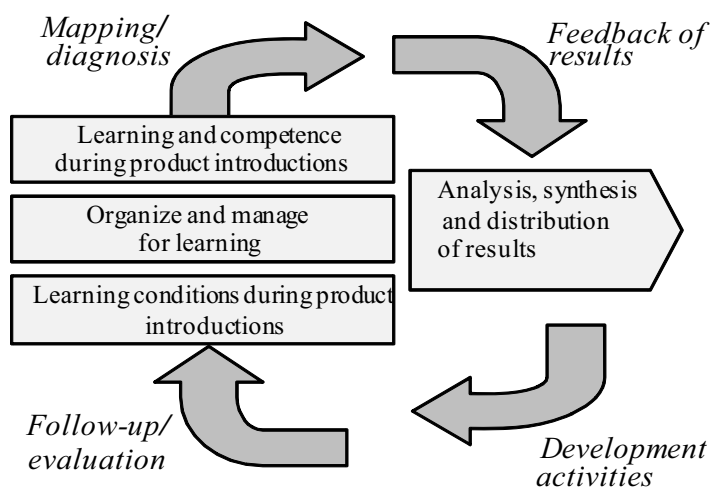

Figure 1 - Illustration of the interactive research approach.

In the mapping/diagnosis phase, qualitative interviews with different groups of employees are performed to learn about the initial status of the company/organization. The result of the mapping is a picture which the researchers then feed back to the participating company/organization for discussion. The definition and analysis of problems are performed jointly by the practitioners and the researchers. Based on the discussion a number of possible development activities are brought forward and selected. The development activities may overlap each other and new development activities may occur throughout the change process. The companies have full responsibility for driving the development activities and any related change processes. These are supported by the researchers through regular discussions about the progress as well as possible investigations made by the researchers. At the end, a follow-up takes place through interviews to evaluate what has occurred in the company throughout the project.

In the approach theoretical and practical knowledge are developed in interplay. The collaboration between researchers and practitioners constitute a common platform through which knowledge is developed [9-11]. The research process is thereby related to practice in the company operations. By interlinking research and practice in this way learning is made possible for both researchers and practitioners, learning which is based on a mutual interest to interpret, understand, develop and suggest different strategies and activities in the ongoing research.

\section{Case study companies and data collection}

\subsection{Case study companies}

The interactive research was carried out in one company producing office products (Company Office) and a company group, consisting of three company units, working with vehicle engines (Company Engine A-C). For an overview of the case companies, see Table 1.

Table 1

Overview of case study companies

\begin{tabular}{|l|l|l|}
\hline Company & $\begin{array}{l}\text { No of employees } \\
\text { (approx })\end{array}$ & Operations \\
\hline Office & 400 & $\begin{array}{l}\text { Development and } \\
\text { production of of- } \\
\text { fice products }\end{array}$ \\
\hline Engine A & 285 & $\begin{array}{l}\text { Production of } \\
\text { engines (including } \\
\text { assembly, painting } \\
\text { and testing) }\end{array}$ \\
\hline Engine B & 50 & $\begin{array}{l}\text { Conversion of } \\
\text { engines to specific } \\
\text { applications }\end{array}$ \\
\hline Engine C & 100 & $\begin{array}{l}\text { Product develop- } \\
\text { ment }\end{array}$ \\
\hline
\end{tabular}

\subsection{Data collection}

Data were collected through qualitative interviews throughout the project's different phases. Semistructured interviews with different groups of employees who were involved in product introductions 
were carried out. The respondents consisted of operators, production engineers, production leaders, testers, process planners, project leaders, engineering designers, purchasers and managers.

For the initial mapping/diagnosis phase, 93 individual interviews were held in total at all companies. There were two main topics in the interview guide: "product introductions" and "learning and competence". The first topic included various aspects related to product introductions, such as different types of product introductions in the participating company units, co-operation and organization, work procedures and routines, problems and problem handling, need for support and improvement suggestions. The second topic included questions about need for current and future competence, learning, acceptance of individual ideas, and utilization of competence and experience.

During the development activities, both individual and group interviews were held, depending on what was suitable in the different activities. All development activities were related to product introductions and learning from different perspectives, so the interview topics reflected this variety of perspectives.

At the ongoing follow-up/evaluation phase, semistructured group interviews were held with employees with different tasks related to product introductions. The interview topics included current status of how product introductions were run, learning and competence utilization in relation to product introductions, and the respondents' view of the research project KNOP.

\section{Results}

\subsection{Mapping/diagnosis and feedback of results}

The mapping showed that a typical product introduction was characterized by strong time pressure, numerous changes in late phases and difficulties to get material and components in time. There were a few key persons who were identified as very important in carrying through the product introductions. Furthermore, there were limited possibilities to prepare production for the new product. For example, prototypes were not taken through the production flow, why any mismatches were not identified in advance. The interview results were categorized into five main themes: 1) Organization and management, 2) Collaboration, 3) Working methods, 4) Problems and problem solving, and 5) Competence develop- ment. These main themes were considered by the authors as conditions for learning and utilization of competences in relation to product introductions.

\subsubsection{Feedback to Company Office}

The feedback of the results from the initial mapping was held at a workshop at the Company Office for discussion and planning of the future work. The researchers presented each of the five themes above. Thereafter, the participants were divided into groups to discuss the following issues:

- What part of the results from the mapping was expected or unexpected?

- What are the development needs in relation to product introductions at the company?

- Prioritize the proposed development activities and suggest a time range for implementation (one year, three years or longer?).

\subsubsection{Feedback to Company Engine units}

In the case of the Company Engine, the results of the initial mapping were presented and discussed in a workshop with representatives from the three company units. First, the researchers presented the results of the mapping, highlighting one of the five themes at a time. For each theme, all three company units' results were presented in a way that allowed a comparison and showed any similarities and differences. After the presentation and clarification of the picture which had evolved through the mapping, the company representatives were placed in crossorganizational discussion groups to identity possible development activities, see [12] for earlier reporting of this process.

Based on the identified development activities, the following four areas were prioritized: i) increased organized collaboration between purchase, production and product development, ii) securing human resources initially in a project, iii) increased use of pro-active methods such as Design for Assembly, Process Failure Mode Effect Analysis (Process FMEA) and common access to information on the internal web-site, and iv) organization of forums for sharing experience. The workshop constituted the first time ever that production and product development jointly discussed product introductions.

\subsection{Development activities}

\subsubsection{General picture}

There were different types of development activities run in the participating companies. Some in- 
volved activities run by the companies themselves and with regular feedback to the researchers, while others constituted in-depth studies of certain ongoing projects at the companies to highlight different issues related to product introductions. Examples of topics for development activities included:

- The development and/or use of an overall project model for both product and production development

- Development of professional project leaders

- Improved documentation and project follow-up

- Collaboration between purchase and product development

- Communication between product development and production

- Follow-up on specific ongoing product introductions

\subsubsection{One specific development activity at Company} Office

One of the development activities at Company Office involved a real-time investigation of a product introduction in order to highlight the work procedures and evaluate the newly adopted overall project model.

This specific product introduction was particular in the sense that it involved a product from the highquality segment. Furthermore, for the first time product development was to be performed in Sweden and direct industrialization in a Chinese subsidiary company. Normal procedure was to industrialize the product in Sweden first and after achieving a stable production to transfer production to China. The product introduction was followed through the perspectives of several groups of employees; project management, product development, marketing and sales as well as different functions at the Chinese subsidiary company, including local project management as well as product and production development.

The researchers' investigation and evaluation of the specific product introduction demonstrated that the intercultural differences and the lack of understanding added to the complexity of the product introduction and that there was a lack in regarding all actors in the two companies as part of a joint work system in relation to the product introduction.

\subsection{Follow-up/evaluation}

The project KNOP is currently in the followup/evaluation phase. The results of the follow-up interviews are being analyzed and will be fed back to each company for reflection of what has occurred during the project and to discuss future activities. These individual company workshops will take place during the autumn/winter of 2011. Preliminary results show that the participating companies have made organizational changes and work in a more structured way with the aid of project models, which may contribute to more efficient product introductions. The preliminary findings also show that the employees have gained deeper knowledge about product introductions and experienced the advantages of working more integrated across functional boundaries.

\subsection{Sharing experiences across companies}

Except for the mapping and development activities carried out in the Company Office and the Company Engine units, the researchers also organized joint cross-company workshops with different themes. After the initial mapping there was one workshop for the participating companies to get to know each other and learn about each others' selected development activities. The second cross-company workshop had the specific theme "Interfaces and boundary crossing for learning in relation to product introductions". At the end of the project a final workshop is planned to highlight and discuss the final results of the interactive research.

In addition to the workshops held within the project KNOP, there was also a workshop held with Company Office and a company outside the project. This workshop took place within the earlier described specific development activity and highlighted the participating companies' mutual interest in the theme "Development and production in collaboration Sweden and China".

\section{Discussion}

The initial mapping in the project KNOP showed that a typical product introduction in the participating companies was characterized by strong time pressure, numerous changes in late phases and other difficulties, which supported earlier research describing the fire-fighting character of product introductions [4-6].

This study as well as earlier studies demonstrate that product introductions are strongly characterized by the challenge to solve multiple practical problems, why a research approach also focusing on these prac- 
tical issues were found suitable by the researchers. The action-learning methodology [9] was found specifically suitable as the project aimed at developing learning in relation to project introductions to strengthen the participating companies' future ability to organize product introductions.

The chosen approach in the project followed the conventional approach of initial mapping/diagnosis, feedback of results, participation in development activities, and follow-up/evaluation. Especially, the development activities constituted an iterative process, in which development activities were selected by the companies, fulfilled and new activities identified. These development activities sometimes overlapped each other and needs for new activities emerged throughout the project. This approach allowed a great deal of flexibility for both researchers and the participating companies to identify and pursue possible activities to learn about and improve the product introduction process.

Another advantage of the interactive research approach is that it proved to be easy to explain to the practitioners. This may sometimes be challenging in relation to research projects.

The interactive research approach offered common arenas for learning between practitioners and researchers. These included feedback sessions, workshops and meetings regarding the development activities. Between these meetings the practitioners worked in the field of practice in pursuing the development activities. At the same time the researchers pursued work in the academic field with analyses, development of theoretical perspectives and/or models, and syntheses of the topic of the project, in this case product introductions. These separate worlds constituted different arenas for learning, the results of which were fed back to each other in the joint arenas.

Product introductions constitute large-scale work systems, involving several groups of employees and often development and/or implementation of new technology. There is a challenge to organize these in an efficient way to support both the individuals and ensure good systems performance. From an ergonomics perspective, this project has mainly focused on organizational ergonomics (macro-ergonomics).

Ergonomics projects are human-centered and involve practice at work and/or human interaction with for instance technology. With the aim of striving towards human involvement in ergonomic changes, the interactive research approach was very suitable. The approach focused on developing practice as much as theory. Furthermore, it was based on full involvement by the practitioners being responsible for carry- ing through the development activities. These aspects indicate that interactive research may be suitable for a variety of fields within ergonomics.

\section{Conclusion}

The study indicates that the participating companies afterwards work in a more structured way with product introductions and that the employees have gained deeper knowledge about product introductions as well as experienced the advantages of working across functional boundaries. Furthermore, the interactive research approach allows for flexibility throughout the project and learning for both practitioners and researchers at different arenas. From an ergonomics perspective, the approach is also suitable as it focuses on developing both practice and theory, it is human-centered, and it emphasizes broad participation from practitioners.

\section{Acknowledgements}

The research project KNOP is financially supported by the Swedish Agency for Innovation Systems (VINNOVA). The results presented in this paper are based on studies carried out at the participating companies to whom the authors owe deep gratitude.

\section{References}

[1] C. Terwiesh, R.E. Bohn and K.S. Chea, International product transfer and production ramp-up: a case study from the data storage industry, R\&D Management 31(2001), 435-451.

[2] K. Johansen, Collaborative product introduction with extended enterprises, Linköping Studies in Science and Technology, Dissertation No. 943, Linköping University, Sweden, 2005.

[3] M. Bellgran and K. Säfsten, Produktionsutveckling utveckling och drift av produktionssystem, Studentlitteratur, Lund, 2005. (In Swedish).

[4] H. Almgren, Pilot production and manufacturing start-up in the automotive industry - Principles for improved performance, Ph.D. Dissertation, Chalmers University of Technology, Sweden, 1991.

[5] S. Fjällström, K. Säfsten, U. Harlin and J. Stahre, Information enabling production ramp-up, Journal of Manufacturing Technology Management 20(2009), 178-196.

[6] J.K. Liker and D.P. Meier, Toyota talent - developing your people the Toyota way, McGraw-Hill, New York, 2007.

[7] K. Eisenhardt and S.L. Brown, Time pacing: competing in markets that won't stand still, Harvard Business Review, March-April (1998). 
[8] U. Harlin, M. Berglund and P. Gullander, Critical events and factors facilitating realization of planned changes in production, Swedish Production Symposium, Gothenburg, Sweden, 2007.

[9] K. Aagard Nielsen and L. Svensson, Action and interactive research: beyond practice and theory, Shaker Publishing BV, Maastricht, 2006.

[10]P-E. Ellström, J. Eklund, H. Kock, L. Lindström and U. Melin, Knowledge creation through collaborative research - an emerging model, Falun, Sweden, 1999.
[11]L. Svensson, G. Brulin, P-E. Ellström and Ö. Widegren, Interaktiv forskning - för utveckling av teori och praktik, Arbetslivsinstitutet, Stockholm, 2002. (In Swedish).

[12]M. Berglund, U. Harlin, M. Gustavsson and K. Säfsten, Development activities in product introductions - a crossfunctional approach, in: Human Factors in Organizational Design and Management - X, M. Göbel, ed., 2011. 